reduces the amplitude of miniature end plate potentials. One possibly analogous case in man has been described, in which a patient noted weakness within 24 hours of beginning penicillamine, improving immediately when the drug was stopped. ${ }^{2}$ Equally this binding suggests a mechanism for antigenic alteration of acetylcholine receptor and loss of tolerance.

Carbocysteine is structurally similar to penicillamine, and people with a low capacity for producing sulphoxides of carbocysteine may be similarly unable to metabolise penicillamine. Poor sulphoxidisers of carbocysteine are more likely to develop proteinuria or thrombocytopenia when taking penicillamine. ${ }^{3}$ Our patient was a very poor sulphoxidiser (index 52). Possibly this inability to metabolise the sulphydryl group makes interaction with acetylcholine receptor more likely.

Penicillamine toxicity, especially proteinuria or marrow suppression, may be more likely in patients who have had a toxic reaction to gold. The order of treatment with gold and penicillamine probably makes no difference to recurrence of toxicity. ${ }^{5}$

Caution should be exercised in prescribing gold to a patient who has developed penicillamine induced myasthenia.

${ }^{1}$ Bever CT, Hai Wang Chang, Penn AS, Jaffe IA, Bock E. Penicillamine induced myasthenia gravis: effects of penicillamine on acetylcholine receptor. Neurology $1982 ; 32: 1077-82$.

2 Atcheson SG, Ward JR. Ptosis and weakness after start of D-penicillamine therapy. Ann Intern Med 1978;89:939-40.

3 Panayi GS, Huson G, Shah RR, et al. Deficient sulphoxidation status and D-penicillamine toxicity. Lancet $1983 ; \mathrm{i}: 414$

${ }^{4}$ Smith PJ, Swinburn WR, Swinson DR, Stewart IM. Influence of previous gold toxicity on subsequent development of penicillamine toxicity. Br Med f 1982;285:595-6.

s Steves MM, Hunter JA, Murdoch RM, Capell HA. Does the order of second-line treatment in rheumatoid arthritis matter? $\mathrm{Br}$ Med $\mathcal{F}$ $1982 ; 284: 79-81$

(Accepted 23 September 1983)

Department of Neurology, Queen Elizabeth Hospital, Birmingham B15 2TH

A P MOORE, MB, MRCP, registrar

A C WILLIAMS, MD, MRCP, consultant neurologist

Good Hope Hospital, Sutton Coldfield, West Midlands

P HILLENBRAND, MB, FRCP, consultant physician

Correspondence to: Dr A P Moore, Glasgow University Department of Neurology, Institute of Neurological Sciences, Southern General Hospital, Glasgow G51 4TF.

\section{Normal energy intake in undernourished patients with Crohn's disease}

Malnutrition is common in Crohn's disease and an important cause is widely believed to be reduced food intake as a consequence of anorexia or fear of abdominal pain. Scientific data, however, are remarkably few. We have investigated the energy intakes of a group of chronically malnourished outpatients with Crohn's disease and compared the results with those in a group of well nourished outpatients with ulcerative colitis and a group of healthy subjects.

\section{Patients, methods, and results}

We studied 26 patients (17 men) with Crohn's disease and 22 (12 men) with ulcerative colitis. All were ambulant and attending a gastrointestinal clinic, and their mean ages (1 SD) were 36 (14) and 43 (14) years, respectively. Mean duration of disease was 10 years in the patients with Crohn's disease and eight years in those with ulcerative colitis. We also studied 22 healthy subjects (13 men), whose mean age (1 SD) was 34 (15) years.

Patients with inflammatory bowel disease had their height and weight measured, their weight being expressed as a percentage of ideal. ${ }^{1} \mathrm{~A}$ semiweighed dietary assessment was carried out in all subjects. ${ }^{2}$ Subjects were provided with a pair of Salter Slimmer's Scales and asked to complete a three day dietary diary on two weekdays and one weekend day, recording everything they ate and drank, using either weight, volume, or handy measures. Mean daily energy intake was calculated using a computer tape of McCance and Widdowson's The Composition of Foods ${ }^{3}$ and from manufacturers' information. Statistical analysis was by unpaired Student's $t$ test.

Mean weight (1 SD) was $86.8(6.4) \%$ of ideal in patients with Crohn's disease and $113.8(19.9) \%$ of ideal in those with ulcerative colitis. The figure shows the mean daily energy intakes of the three groups; there were no significant differences.

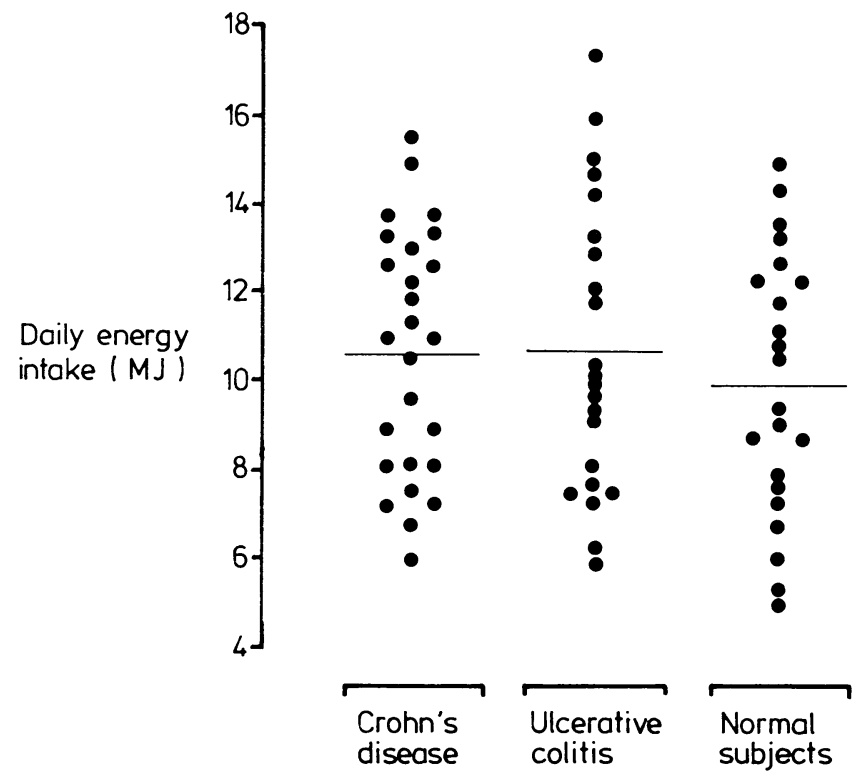

Daily energy intakes in patients with Crohn's disease, patients with ulcerative colitis, and normal subjects. Bars represent group means.

Conversion: SI to traditional units-Energy: $4 \cdot 18 \mathrm{MJ} \approx 1000 \mathrm{kcal}$.

\section{Comment}

These results show that malnourished outpatients with Crohn's disease have similar energy intakes to those of well nourished outpatients with ulcerative colitis and healthy subjects. Undernutrition might therefore be accounted for by malabsorption, inflammation, and enteric loss of nutrients, and possibly the increased metabolic demands of the disease cannot be compensated for by an apparently normal energy intake. In undernourished ambulatory patients with Crohn's disease increasing the energy intake by enteral supplementation may result in an increase in weight and other nutritional variables. ${ }^{4}$ Similarly parenteral hyperalimentation in acute severe Crohn's disease may improve nutrition and contribute to primary management. ${ }^{5}$ These observations support the concept that undernourished patients with Crohn's disease may have a "relative energy deficiency."

Our study suggests that a reduced food intake is not a common feature in chronically undernourished patients with Crohn's disease; nevertheless, this does not in any way obviate the important role of nutritional care in their management.

1 Society of Actuaries. Build and blood pressure studies. Vols 1 and 2. Chicago, 1959.

${ }^{2}$ Nelson $M$, Nettleton P. Dietary survey methods. I : A semi weighed technique for measuring dietary intake within families. F Hum Nutr 1980;34: 325-8.

3 Paul AA, Southgate DAT. McCance and Widdowson's the composition of foods. HMSO, 1978.

${ }^{4}$ Harries AD, Jones LA, Danis V, et al. Supplemented oral nutrition in Crohn's disease. A controlled trial. Lancet 1983;i:887-90.

5 Reilly J, Ryan JA, Strole W, Fischer JE. Hyperalimentation in inflammatory bowel disease. Am $\mathcal{F}$ Surg 1976;131:192-200.

(Accepted 30 November 1983)

Departments of Dietetics and Gastroenterology, University Hospital of Wales, Heath Park, Cardiff CF4 4XW

L A JONES, SRD, senior dietitian

A D HARRIES, MA, MRCP, senior lecturer in medicine

J RHODES, MD, FRCP, consultant gastroenterologist

Department of Medicine, St James's University Hospital, Leeds

R V HEATLEY, MD, MRCP, senior lecturer in medicine

Correspondence to: Mrs L A Jones. 